\title{
Growth, Characterization, and Stability Testing of Epitaxial MgO (100) on GaAs (100)
}

K. Mudiyanselage, M. A. Nadeem, H. A. Raboui, H. Idriss*

Hydrogen Platform, Catalysis Department,

SABIC-Corporate Research and Development (CRD) at KAUST, 23955-Thuwal, Saudi Arabia

\begin{abstract}
Epitaxial $\mathrm{MgO}$ (100) films have been grown on GaAs (100) by evaporation of $\mathrm{Mg}$ in the presence of $5 \times 10^{-6}$ Torr of oxygen. Prior to the growth of $\mathrm{MgO}$, the GaAs (100) substrate was cleaned by Ar ion sputtering and annealing. $\mathrm{MgO}$ (100) on GaAs (100) was in situ characterized with Auger electron spectroscopy (AES), and ex situ by scanning electron microscopy (SEM), X-ray diffraction (XRD), highresolution transmission electron microscopy (HRTEM), and energy-dispersive X-ray spectroscopy (EDX). X-ray diffraction patterns indicated that the $\mathrm{MgO}$ film has grown predominantly in the cubic phase with the (100) plane parallel to the GaAs (100) substrate. HRTEM results have confirmed the epitaxial growth of $\mathrm{MgO}$ with $\mathrm{MgO}$ (100)[001]\| GaAs (100)[001]. Despite the high lattice misfit, the epitaxial $\mathrm{MgO}(100)$ is grown on GaAs (100) due to the $4: 3$ relationship (4 aMgO : $3 \mathrm{aGaAs}$ ) between $\mathrm{MgO}$ (100) and GaAs (100). The formation of a 4:3 superstructure reduces the lateral misfit between $\mathrm{MgO}(100)$ and $\mathrm{GaAs}(100)$ to $\approx 0.65 \%$. To test the potential of $\mathrm{MgO}$ as a protection layer for III-V semiconductor based photo-electro catalytic devices for water splitting in alkaline media the reaction of $\mathrm{MgO}$ films with $\mathrm{H}_{2} \mathrm{O}$ and $\mathrm{NaOH}$ was investigated. Flake-like $\mathrm{Mg}(\mathrm{OH})_{2}$ structures appear to have formed on top of the $\mathrm{MgO}$ films treated with $\mathrm{NaOH}$.
\end{abstract}

\section{Key words}

Epitaxial $\mathrm{MgO}$ (100) films; GaAs (100); flake-like $\mathrm{Mg}(\mathrm{OH})_{2}$ structures; $\mathrm{MgO}$ (100) grown on GaAs (100); lateral misfit between $\mathrm{MgO}$ (100) and GaAs (100).

*Corresponding author’s Email: idrissh@sabic.com 


\section{Introduction}

Growth of epitaxial $\mathrm{MgO}$ thin films on GaAs substrates has received considerable attention, due to unique electronic properties of $\mathrm{MgO} / \mathrm{GaAs}$ systems [1, 2]. In previous studies, $\mathrm{MgO}$ films were grown on GaAs (100) mainly by direct evaporation instead of $\mathrm{Mg}$ in the presence of $\mathrm{O}_{2}$ using different techniques. In some studies, reactive magnetron sputtering was applied to deposit $\mathrm{MgO}$ directly on $\mathrm{GaAs}$ $[3,4]$. Direct deposition of $\mathrm{MgO}$ by electron beam evaporation without additional oxygen was also reported previously [1, 5-7]. Lu et al. used an evaporation cell to deposit MgO directly.[8, 9] Electron beam evaporation of $\mathrm{MgO}$ in the presence of $\mathrm{O}_{2}$ was also applied to deposit $\mathrm{MgO}$ on $\mathrm{GaAs}(100)[9]$. Nashimoto et al. applied pulsed laser deposition (PLD) method to deposit $\mathrm{MgO}[10,11]$. In most studies, good epitaxial growth of $\mathrm{MgO}$ on $\mathrm{GaAs}(100)$ was observed in the temperature range of $400-600{ }^{\circ} \mathrm{C}$, while others reported a polycrystalline $\mathrm{MgO}$ morphology with a preferential (100) growth [4] or showed an amorphous $\mathrm{MgO}$ intermediate layer at the interface at lower temperatures [12].

Only two studies reported the growth of $\mathrm{MgO}$ on $\mathrm{GaAs}$ by evaporating pure $\mathrm{Mg}$ metal in the presence of oxygen. Pulsed DC magnetron sputtering was used to grow $\mathrm{MgO}$ on GaAs using pure $\mathrm{Mg}$ metal as the target material in the presence of a high-purity gas having the composition of $\mathrm{O}_{2}-\mathrm{Ar}, 1-$ $7.5 \% \mathrm{O}_{2}$ at a total pressure of $5 \times 10^{-3}$ Torr [13]. Nashimoto et al. applied laser ablation for the deposition of $\mathrm{MgO}$ using $\mathrm{Mg}$ target and the film quality was very sensitive to the amount of the oxygen present in the system[10]. In our study, we evaporated $\mathrm{Mg}$ using an effusion cell in the presence $\mathrm{O}_{2}$ to grow $\mathrm{MgO}$ films on GaAs (100). One advantage of this method is that $\mathrm{Mg}$ evaporates at lower temperature than that required for the evaporation of $\mathrm{MgO}$. Although in this case, a high oxygen flux $\left(\sim 10^{-6} \mathrm{Torr}\right)$ is required to avoid the desorption of $\mathrm{Mg}$ atoms from the substrate. [14] This is in contrast to the direct deposition of $\mathrm{MgO}$ where a beam of $\mathrm{MgO}$ molecules can be obtained by electron beam evaporation and $\mathrm{MgO}$ films can be grown at lower pressures.[14] It is important to note that gas phase $(\mathrm{MgO})_{n}$ clusters do form and each would have different sticking coefficient on the substrate depending on its structure as well as the number of formula units, $n$.

One of the main issues affecting epitaxial growth of $\mathrm{MgO}$ on GaAs (100) is the quality of the GaAs (100) surface prior to $\mathrm{MgO}$ deposition. The presence of surface impurities, roughness, and a layer of oxide can strongly affect both epitaxy and interface properties. Therefore, in some of the studies mentioned above, first GaAs films were prepared in situ and then $\mathrm{MgO}$ was deposited [1, 4, 7, 8, 15, 16]. In other studies, commercially polished $\mathrm{GaAs}(100)$ wafers were used after cleaning by wet chemical methods $[3,5,9,10,14,17]$. In addition, oxide desorption by annealing at higher temperatures in the absence of As flux was used previously for cleaning the GaAs surface [18]. However, often these wet 
chemical and annealing methods failed to achieve clean atomically smooth GaAs surfaces and oxide removal was only partial. The best results were achieved by preparing a GaAs (100) layer in situ using standard molecular beam epitaxy (MBE) [19-21]. In our study, GaAs (100) substrate was cleaned and prepared for the growth of $\mathrm{MgO}$ by Ar ion sputtering and annealing without using chemical etching or wet chemical methods.

In addition to unique electronic properties of $\mathrm{MgO} / \mathrm{GaAs}$ systems, $\mathrm{MgO}$ can be used as a light penetrating film due to its high band gap. $\mathrm{MgO}$ films, which are thicker than $3 \mathrm{~nm}$, have the bulk $\mathrm{MgO}$ band gap of $7.83 \mathrm{eV}$ [16]. Therefore, $\mathrm{MgO}$ allows passing the whole range of solar radiation hence it may be able to use as a light penetrating protective layer for photo catalysts to avoid photo corrosion in processes associated with solutions or electrolytes such as photo catalytic water splitting and photo oxidation of organics. In order to use $\mathrm{MgO}$ as a protective interlayer to separate the surfaces of photo catalysts from solutions or electrolytes to avoid photo corrosion, $\mathrm{MgO}$ layer must be stable under reaction conditions. In addition, $\mathrm{MgO}$ films must be capable of transferring charge carriers efficiently from semiconductor photo catalysts to the surface of $\mathrm{MgO}$ where photo catalytic reactions take place.

Here we report the growth of $\mathrm{MgO}$ films on $\mathrm{GaAs}$ (100) by evaporating $\mathrm{Mg}$ in the presence of oxygen. The grown $\mathrm{MgO}$ films were characterized with different techniques including in situ Auger electron spectroscopy (AES), and ex-situ scanning electron microscopy (SEM), X-ray diffraction (XRD), high-resolution transmission electron microscopy (HRTEM), and energy-dispersive X-ray spectroscopy (EDX)). To study the stability of $\mathrm{MgO}$ films under aqueous conditions, we investigated the reaction of $\mathrm{MgO}$ films with water and with $0.1 \mathrm{M} \mathrm{NaOH}$.

\section{Experimental}

$\mathrm{MgO}$ films on GaAs (100) were grown in a molecular beam epitaxy (MBE) chamber with a base pressure of $\approx 3.0 \times 10^{-10}$ Torr. An effusion cell (CreaTec Fischer \& Co.) was used for Mg evaporation. The MBE system is also equipped with Auger Electron Spectroscopy (AES - STAIB, ESA 100), mass spectrometry (SRS, RGA 200), and Ar ion sputtering (Ion Source IQE 11/35, SPECS). The Zn-doped (carrier concentration $=1.17 \times 10^{19}-2.18 \times 10^{19} \mathrm{~cm}^{-3}$; the total numbers of atoms in $1 \mathrm{~cm}^{3}$ of GaAs is 4.42 $\times 10^{22}$ so the doping is ca. $0.02-0.05 \%$ ) GaAs (100) single crystal wafer (AXT, Inc.) was used to grow $\mathrm{MgO}$ films. The temperature of the sample stage was measured by a type-K thermocouple attached to it and the temperature of the GaAs (100) substrate was estimated using a previous temperature calibration performed for the Ti-film/Si (100) substrate by measuring its temperature with a pyrometer. The $\operatorname{GaAs}(100)(1 \mathrm{~cm} \times 1 \mathrm{~cm})$ substrate was cleaned by Ar ion sputtering $\left(600 \mathrm{~V}, \approx 2 \times 10^{-5}\right.$ Torr of Ar) for 
$\sim 30 \mathrm{~min}$ at $500{ }^{\circ} \mathrm{C}$ and subsequent annealing at $550{ }^{\circ} \mathrm{C}$ for one hour. The purity of the substrate was determined by the AES. MgO films on GaAs (100) were grown by evaporation of $\mathrm{Mg}$ with the effusion cell (the effusion cell temperature was set at $240{ }^{\circ} \mathrm{C}$ ). The substrate was first heated to $450{ }^{\circ} \mathrm{C}$ in vacuum, then the shutter of the $\mathrm{Mg}$ doser was opened, next the substrate was turned towards the $\mathrm{Mg}$ doser and finally $\mathrm{O}_{2}$ was introduced into the chamber $\left(5 \times 10^{-6}\right.$ Torr). The thickness of the film was dictated by the deposition time under a constant $\mathrm{Mg}$ flux and approximately $20 \mathrm{~nm}$ film was grown after a threehour deposition.

XRD data were collected with D8 ADVANCE (Bruker) X-ray diffractometer and SEM micrographs were obtained with Verios G4 Scanning Electron Microscope (Thermo Scientific). The cross-sectional MgO/GaAs (100) lamella was prepared using Focused Ion Beam (FIB) technique for HRTEM analysis. Prior to ion-beam milling, $\mathrm{MgO}$ deposited GaAs (100) wafer was attached to an $\mathrm{Al}$ pin stub using strips of $\mathrm{Cu}$ tape. Approximately $10 \mathrm{~nm}$ layer of Ir was deposited using Q150T Plus turbomolecular pumped sputter coater to avoid charging during the FIB milling process. First, approximately 25-50 nm amorphous carbon layer was deposited on the area of interest using an electron beam $(3 \mathrm{kV}, 2.7 \mathrm{nA})$. Then approximately a 450-500 nm Pt layer was deposited first using the electron beam $(3 \mathrm{kV}, 2.7 \mathrm{nA})$ followed by further Pt deposition using an ion beam $(30 \mathrm{kV}, 0.28 \mathrm{nA})$. Due to observable damage to the $\mathrm{MgO}$ film at typical beam energy values used for preparing lamellae of $\mathrm{Si}$ wafer, much lower beam energies were used to avoid any possible damage to the $\mathrm{MgO}$ thin film during milling and thinning processes. Typically, the lamella preparation process took about 4-5 hours. Finally,

a very thin $(\approx 100 \mathrm{~nm})$ lamella was prepared for HRTEM, STEM, and EDX measurements. HRTEM analysis was performed with Titan ST transmission electron microscope equipped with a field emission electron source, which was operated at $300 \mathrm{kV}$. The microscope was operated in either HRTEM (phase contrast) or HAADF-STEM mode (Z-contrast). The point-to-point resolution was $0.12 \mathrm{~nm}$ and the information limit was $0.10 \mathrm{~nm}$. HRTEM beam focus was $100 \mathrm{~nm}$ whereas that of STEM was $1.0 \mathrm{~nm}$. EDX analysis was carried out in STEM mode of operation. A double tilt sample holder was used to align the lamella on $\mathrm{MgO}, \mathrm{GaAs}$, and $\mathrm{MgO} / \mathrm{GaAs}$ interface zone axes.

\section{Results and Discussion}

\subsection{Preparation and characterization of $\mathrm{MgO}$ films}

\subsubsection{Auger electron spectroscopy (AES) data}

Figure 1 presents Auger Electron Spectra before and after deposition of an $\mathrm{MgO}$ film on GaAs (100) with the following procedure. First, the GaAs (100) substrate was cleaned by Ar ion sputtering at 
$500{ }^{\circ} \mathrm{C}$ for 30 minutes and subsequent annealing at $550{ }^{\circ} \mathrm{C}$ for one hour. Then AES lines of the cleaned GaAs (100) substrate was obtained as shown by the black spectrum. Before cleaning the GaAs (100) substrate, $\mathrm{C}, \mathrm{Ca}$, and $\mathrm{O}$ were seen; all were removed after the cleaning process. The $\mathrm{MgO}$ film was grown at $450{ }^{\circ} \mathrm{C}$ substrate temperature by evaporating $\mathrm{Mg}$ under $5.0 \times 10^{-6}$ Torr of $\mathrm{O}_{2}$ for three hours. The Mg effusion cell temperature was kept at $240{ }^{\circ} \mathrm{C}$. After deposition of $\mathrm{MgO}$, the peaks for $\mathrm{Ga}$ and As were not detected as shown by the red spectrum where only AES peaks for Mg and O were present. The peak-to-peak height ratio of $\mathrm{Mg}(\mathrm{KLL}) / \mathrm{O}(\mathrm{KLL})$ after incorporating the AES sensitivity factors [O (KLL) - 0.50 and $\mathrm{Mg}(\mathrm{KLL})-0.11]$ is $\approx 1.0(\mathrm{Mg}: \mathrm{O} \approx 1.0: 1.0$ ). These results indicate that a continuous $\mathrm{MgO}$ film is grown on $\operatorname{GaAs}(100)$ and it is thick enough so that peaks for the underneath substrate $\operatorname{GaAs}(100)$ are not detected (95\% of the signal originated from $3 \lambda \approx 9 \mathrm{~nm}$ ) where $\lambda(\mathrm{nm}) \approx 3 \mathrm{~nm}[22],[23]$ for the $\mathrm{KE}_{\mathrm{As}(\mathrm{LMM})}=1258 \mathrm{eV}$ ). Considering a $\mathrm{d}_{\mathrm{MgO}}$ spacing of $0.21 \mathrm{~nm}$ (half of the $\mathrm{MgO}$ lattice constant) we estimated $\lambda=1.5 \mathrm{~nm}$; using the equation $\lambda(\mathrm{nm})=0.41 \times \mathrm{d}^{1.5} \mathrm{MgO} \times \mathrm{KE}^{0.5}{ }_{\operatorname{GaAs}(\mathrm{LMM})}[24,25]$.
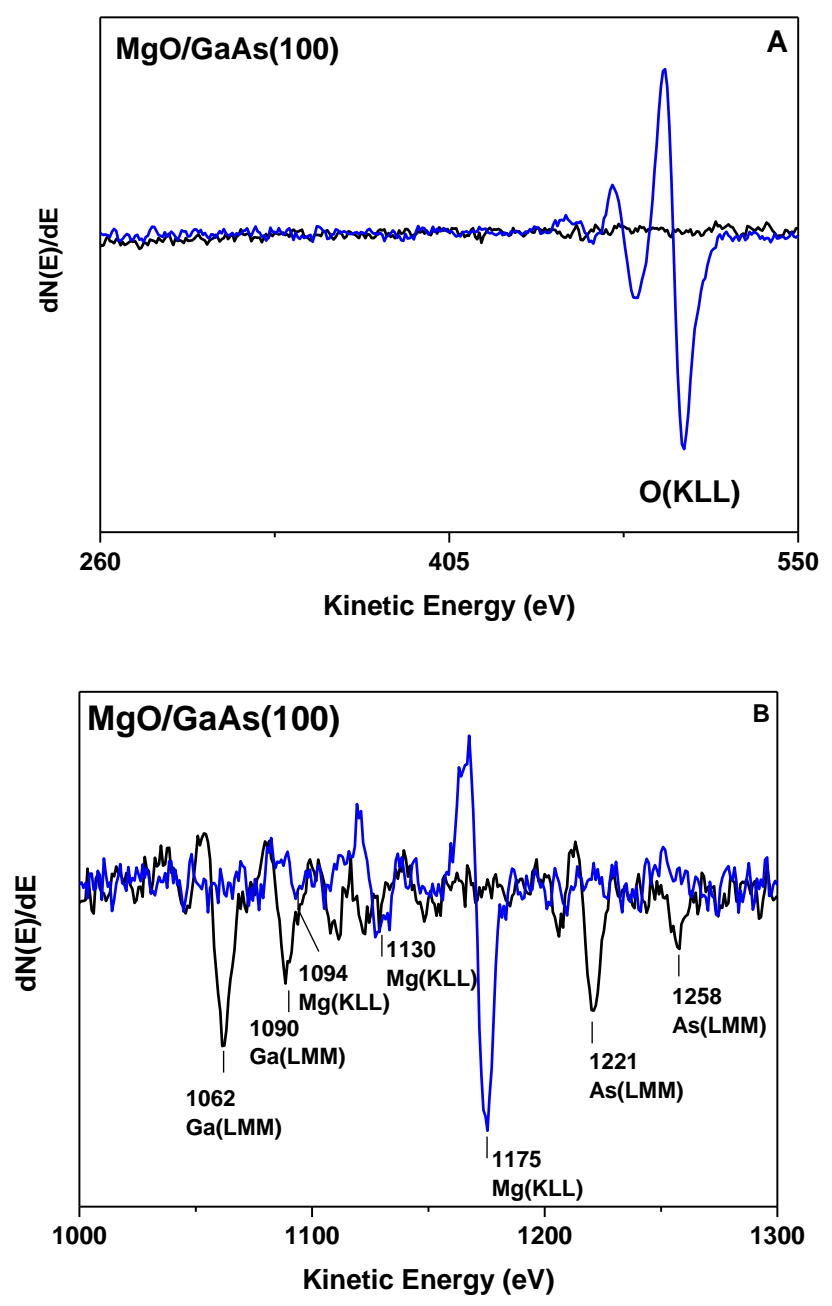


\section{Figure 1.}

Auger electron spectra before (black) and after (blue) deposition of an $\mathrm{MgO}$ film on GaAs (100) at the following experimental conditions. The GaAs (100) substrate was cleaned by Ar ion sputtering at 500 ${ }^{\circ} \mathrm{C}$ for 30 minutes and subsequent annealing at $550{ }^{\circ} \mathrm{C}$ for one hour. The $\mathrm{MgO}$ film was grown at 450 ${ }^{\circ} \mathrm{C}$-substrate temperature by evaporating $\mathrm{Mg}$ under $5.0 \times 10^{-6}$ Torr of $\mathrm{O}_{2}$ for three hours. The $\mathrm{Mg}$ cell temperature was kept at $240{ }^{\circ} \mathrm{C}$. A) The $\mathrm{dN}(\mathrm{E}) / \mathrm{dE}$ AES O KLL region before and after deposition. B) The dN(E)/dE AES Mg KLL, Ga LMM and As LMM regions before and after deposition.

\subsubsection{X-ray diffraction (XRD) data}

Figure 2 presents an XRD spectrum of $\mathrm{MgO} / \mathrm{GaAs}$ (100) where the $\mathrm{MgO}$ film was grown at 450 ${ }^{\circ} \mathrm{C}$. The XRD spectrum exhibits an $\mathrm{MgO}$ (200) peak for the $\mathrm{MgO}$ film and GaAs substrate peaks, (200) and (400), indicating that the $\mathrm{MgO}$ film has grown predominantly in the cubic phase with the (100) plane parallel to the substrate. Two possible heteroepitaxial relationships between GaAs (100) and $\mathrm{MgO}$ planes, MgO [110]\|GaAs [100] and MgO [100] $\|$ GaAs [100], have been reported [3]. The lattice constants of $\mathrm{GaAs}$ and $\mathrm{MgO}$ are 5.6538 and $4.213 \AA$, respectively[3].

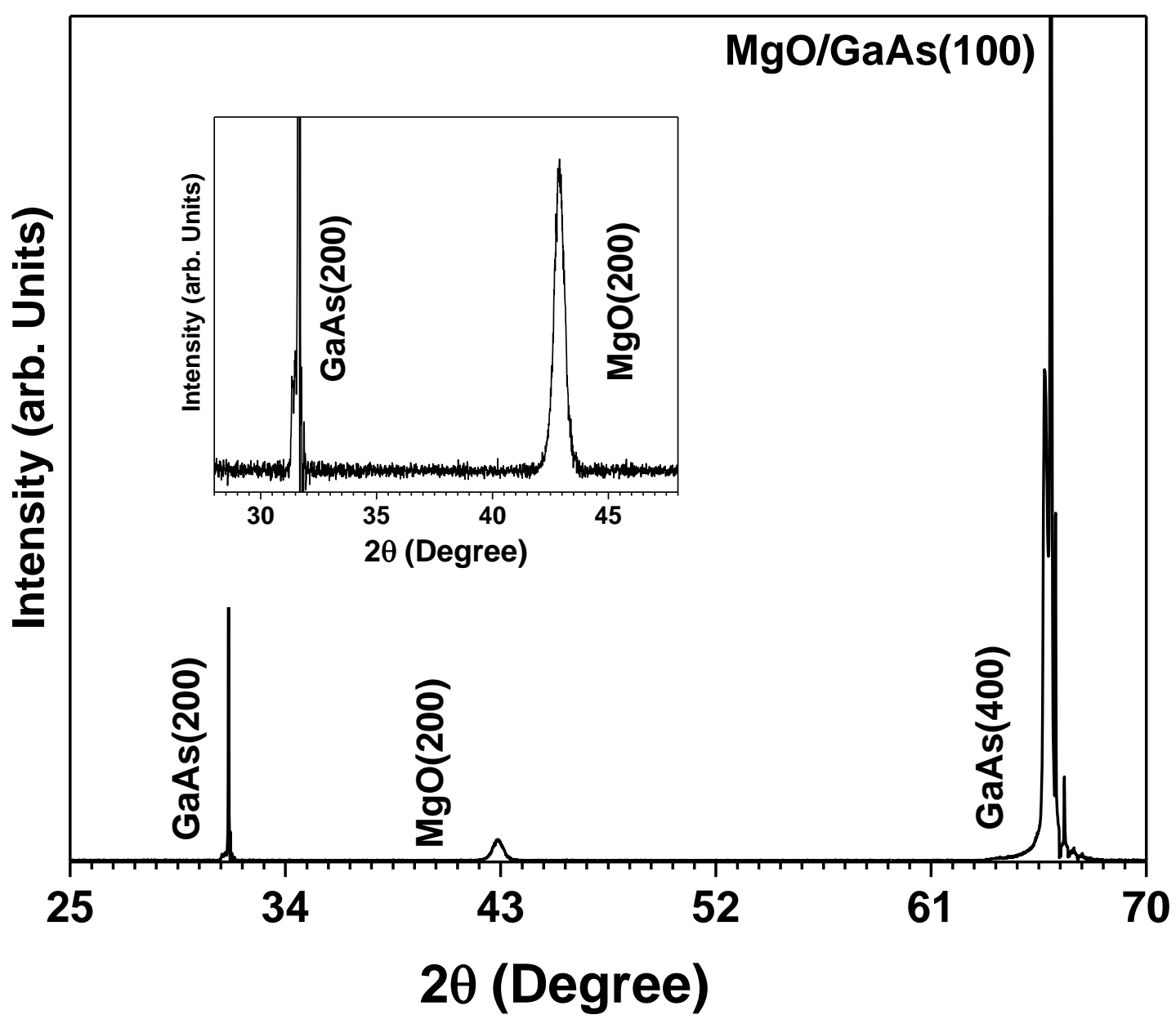




\section{Figure 2.}

X-ray diffraction pattern of an $\mathrm{MgO}$ film grown on GaAs (100) at $450{ }^{\circ} \mathrm{C}$. The inset is a magnifying region of the GaAs (200) and $\mathrm{MgO}$ (200) diffraction patterns.

The lattice misfit [(aGaAs - aMgO)/aMgO][1] of heteroepitaxial relationship between $\mathrm{MgO}[100] \|$ $\operatorname{GaAs}[100]$ is $34.2 \%$ whereas it is $5.1 \%$ for $\mathrm{MgO}[110] \| \mathrm{GaAs}[100]$ heteroepitaxial relationship. Despite the higher misfit, the XRD data shows that $\mathrm{MgO}$ (100) is grown on GaAs (100). However, in order to see the growth configuration and to see whether it is epitaxial growth, analysis by other techniques such as TEM and reflection high-energy electron diffraction (RHEED) is required. The HRTEM analysis of $\mathrm{MgO} / \mathrm{GaAs}$ (100) are shown in section 3.1.4.

In the XRD spectrum, the position of $\mathrm{MgO}(200)$ peak is at $42.9^{\circ}$, which is very close to values reported for a $\mathrm{MgO}$ film grown on $\mathrm{GaAs}(100)$ and bulk $\mathrm{MgO}$ crystals at $42.92^{\circ}$ and $42.89^{\circ}$, respectively [3]. These XRD results suggest that the $\mathrm{MgO}$ film grown on GaAs (100) has bulk properties. The full width at half maximum (FWHM) of the $\mathrm{MgO}(200)$ peak is 0.52 , which is similar to the FWHM of 0.6 reported previously for a $\mathrm{MgO}(100)$ film grown on $\mathrm{GaAs}(100)$ at $200{ }^{\circ} \mathrm{C}[1]$. In general, the FWHM decreases with increasing growth temperature due to better crystalline ordering of films. The $\mathrm{MgO}$ films on $\operatorname{GaAs}(100)$ grown at 250, 300, 350, 400, and $450{ }^{\circ} \mathrm{C}$ temperatures had FWHM (XRD) peaks equal $0.70,0.70,0.70,0.52$, and $0.52^{\circ}$, respectively.

\subsubsection{Scanning electron microscopy (SEM) data}

The SEM micrographs of $\mathrm{MgO}$ films grown on GaAs (100) at $450{ }^{\circ} \mathrm{C}$ are shown in Figure 3 . The SEM micrograph obtained immediately after preparing the $\mathrm{MgO}$ film is presented in Figure 3A, where a nearly featureless structure is seen with no signs of granular crystallites indicating that the film grown at $450{ }^{\circ} \mathrm{C}$ is smooth. The SEM micrograph in Figure $3 \mathrm{~B}$ was obtained after exposing the $\mathrm{MgO}$ film to air for $\approx$ six hours, some white regions or spots are seen. $\mathrm{MgO}$ when exposed to air reacts with $\mathrm{H}_{2} \mathrm{O}$ and $\mathrm{CO}_{2}$ to form hydroxides, hydrogenocarbonates and carbonates as reported in a previous study [26, 27]. Longer exposure to air led to larger white areas as shown by the SEM micrograph in Figure 3C, obtained after exposing the $\mathrm{MgO}$ film to air for 8 days. Based on the EDX analysis, white areas are $\mathrm{Mg}(\mathrm{OH})_{2}$ and the dark regions may be composed of $\mathrm{MgO}, \mathrm{Mg}\left(\mathrm{HCO}_{3}\right)_{2}$ and $\mathrm{MgCO}_{3}$ (supporting information Figure $\mathrm{S} 1)$. Similar results were obtained after immersing $\mathrm{MgO} / \mathrm{GaAs}(100)$ in water for 5 hours at room temperature as shown by the SEM micrograph in Figure 3D. 

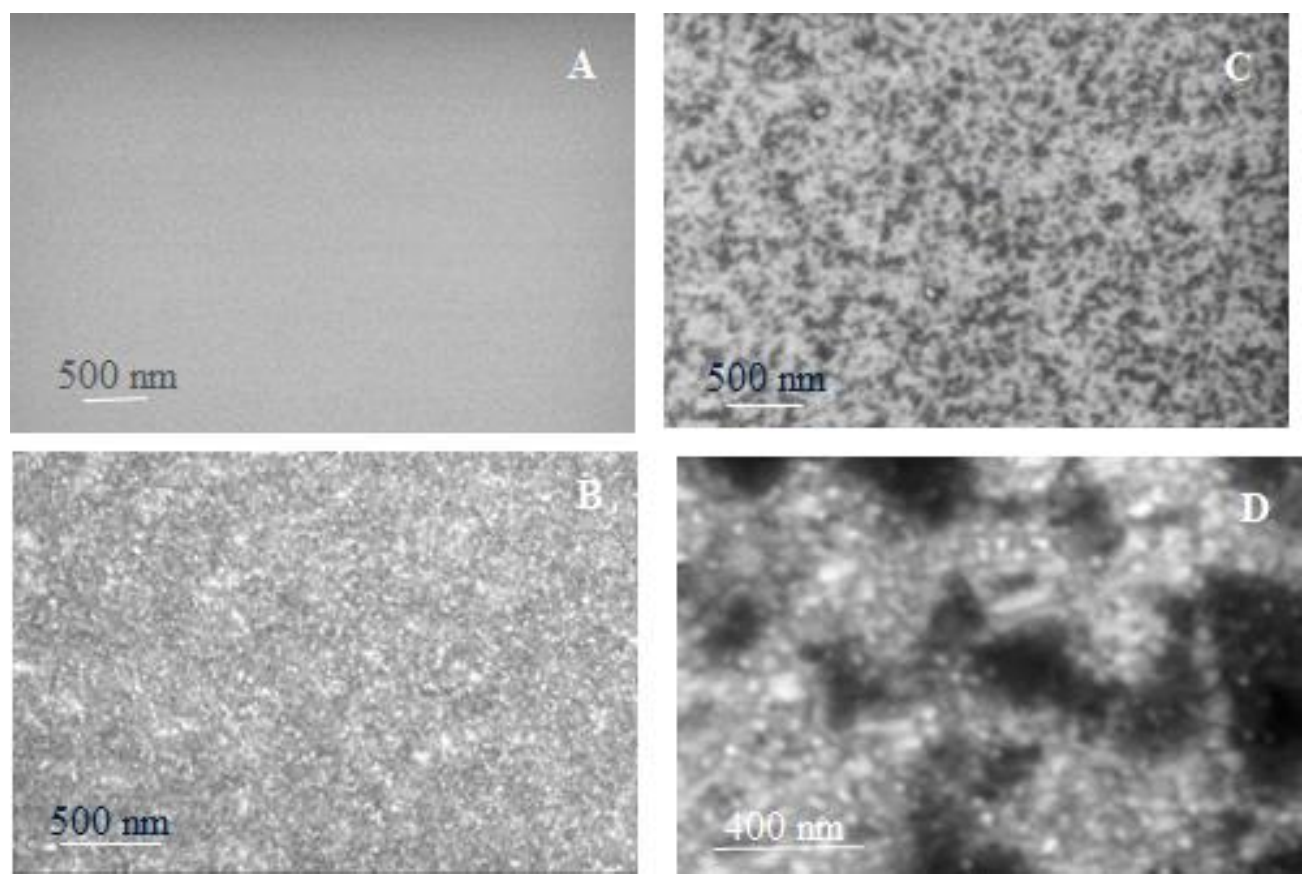

Figure 3.

SEM micrographs of an $\mathrm{MgO}$ film grown on GaAs (100) at $450{ }^{\circ} \mathrm{C}$. A) Fresh after preparing the $\mathrm{MgO}$ film, exposed to ambient conditions before imaging B) Kept in ambient conditions for $\approx$ six hours $\mathrm{C}$ ) Kept in ambient conditions for eight days. D) After immersing $\mathrm{MgO} / \mathrm{GaAs}$ (100) in water for five hours.

\subsubsection{Ttransmission electron microscopy (TEM) and energy-dispersive X-ray spectroscopy (EDX) data}

To see whether the MgO film was grown epitaxially on GaAs (100), cross sectional HRTEM micrographs of an $\mathrm{MgO} / \mathrm{GaAs}$ (100) lamella prepared by FIB milling were obtained. Figure 4A presents the TEM micrograph of an $\mathrm{MgO} / \mathrm{GaAs}$ (100) lamella with $\mathrm{Ir}, \mathrm{C}$, and Pt layers deposited on top of the $\mathrm{MgO}$ film. The thickness of the $\mathrm{MgO}$ layer is $19 \mathrm{~nm}$ whereas the thicknesses of the deposited $\mathrm{Ir}$ and $\mathrm{C}$ layers on top of $\mathrm{MgO}$ film are $\approx 10 \mathrm{~nm}$, and $\approx 35 \mathrm{~nm}$, respectively. Pt layer is present on top of the $\mathrm{C}$ layer. Chemical identities of $\mathrm{MgO}$ and GaAs layers were confirmed by EDX in STEM mode of operation as shown in Figure 4B. Spectrum 1 obtained from region 1 shows peaks for $\mathrm{Mg}$ and $\mathrm{O}$ confirming the presence of $\mathrm{MgO}$. In addition, spectrum 1 presents a peak for $\mathrm{Cu}$ that comes from the $\mathrm{Cu}$ TEM grid. A peak for $\mathrm{C}$ is also present in both spectra. Spectrum 2 collected from region 2 shows peaks for As and $\mathrm{Ga}$ as expected. The FFT images shown in Figures 4C and 4D for $\mathrm{MgO}$ and GaAs, respectively, indicate that they are single crystalline. The insets in Figures 4C and 4D, which present TEM micrographs of $\mathrm{MgO}$ and $\mathrm{GaAs}$ regions, respectively, further confirm that $\mathrm{GaAs}$ and $\mathrm{MgO}$ are single crystalline. 

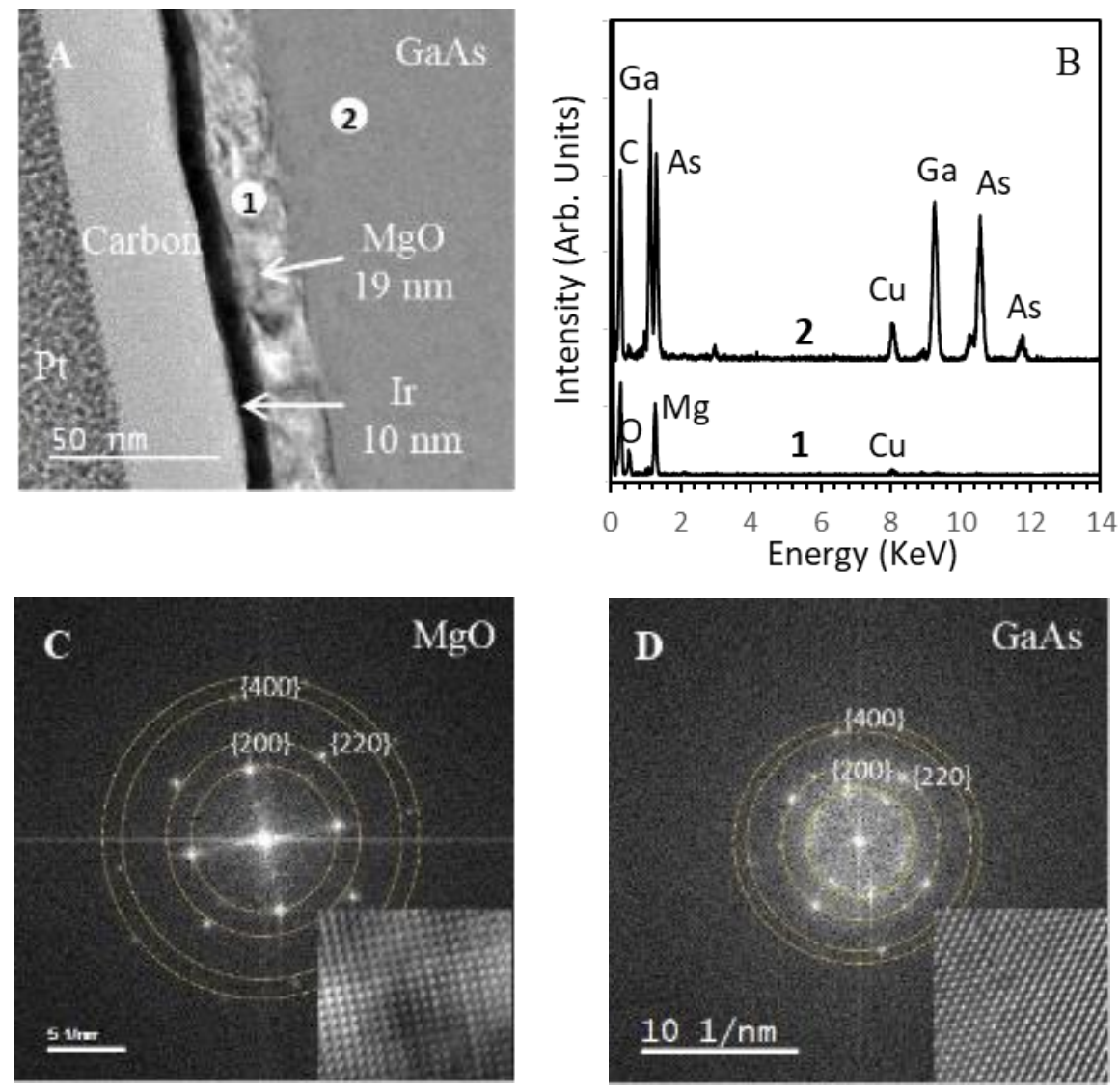

\section{Figure 4.}

A) A cross sectional TEM micrograph of $\mathrm{MgO} / \mathrm{GaAs}$ (100) lamella prepared by FIB milling. Prior to ion-beam milling, layers of $\operatorname{Ir}(\approx 10 \mathrm{~nm}), \mathrm{C}(\approx 35 \mathrm{~nm})$ and $\mathrm{Pt}(\approx 500 \mathrm{~nm})$ were deposited on top of the $\mathrm{MgO}$ film to preserve the surface from damage by high energy $\mathrm{Ga}^{+}$ion beam used for the milling process. B) EDX spectra obtained from the regions 1 and 2 specified in A. C) and D) FFT images of $\mathrm{MgO}$ and $\mathrm{GaAs}$, respectively. Insets present TEM micrographs of $\mathrm{MgO}$ and $\mathrm{GaAs}$.

To see the interface between GaAs and $\mathrm{MgO}$, a cross sectional HRTEM micrograph of the $\mathrm{MgO} / \mathrm{GaAs}$ (100) interface was obtained as shown in Figures 5A and 5B. A clear interface between $\mathrm{MgO}$ and $\mathrm{GaAs}$ is present and it is not distorted when changing from $\mathrm{GaAs}$ to $\mathrm{MgO}$ lattice. The electron beam is oriented along the GaAs [001] direction and the TEM micrograph shows that the MgO film has grown in the cubic phase with the (100) plane parallel to GaAs (100). The insets in Figure 5A present FFT images for $\mathrm{MgO}$ and GaAs obtained from the areas in close proximity to the interface. The FFT images were obtained by keeping one side of the squared ROI (region of interest) in Gatan software on the broken line. The broken line indicates the interface between $\mathrm{GaAs}$ and $\mathrm{MgO}$ and connects the 
meeting points of the straight lines drawn along the lattice planes of both materials ( $\mathrm{MgO}$ followed by GaAs). These FFT images indicate that $\mathrm{MgO}$ and $\mathrm{GaAs}$ located close to the interface are single crystalline as they are exactly the same as the FFT images obtained from $\mathrm{MgO}$ and GaAs regions away from the interface as shown in Figures 4C and 4D, respectively. This also indicates the absence of any significant surface oxidation of $\mathrm{GaAs}$ as distortion in FFT due to the presence of $\mathrm{Ga}_{2} \mathrm{O}_{3}$ or $\mathrm{As}_{2} \mathrm{O}_{3} / \mathrm{As}_{2} \mathrm{O}_{5}$ was not observed. It is to be noted that $\mathrm{Ga}_{2} \mathrm{O}_{3}$ has trigonal, monoclinic and hexagonal as its most commonly found crystal structures [28]. $\mathrm{As}_{2} \mathrm{O}_{3}$ has monoclinic as well as cubic crystal structures [29] while $\mathrm{As}_{2} \mathrm{O}_{5}$ has . orthorhombic and tetragonal crystal structures [30]. The lattice parameters of both oxides differ from the one obtained and therefore their formation can be ruled out [31],[32]. Since HRTEM shows a reconstruction starting from the second layer, and since above this layer the diffraction pattern is that of $\mathrm{MgO}$, then the interface may be composed of $\mathrm{Ga}-\mathrm{O}-\mathrm{Mg}$ and $\mathrm{As}-\mathrm{O}-\mathrm{Mg}$ bonds.
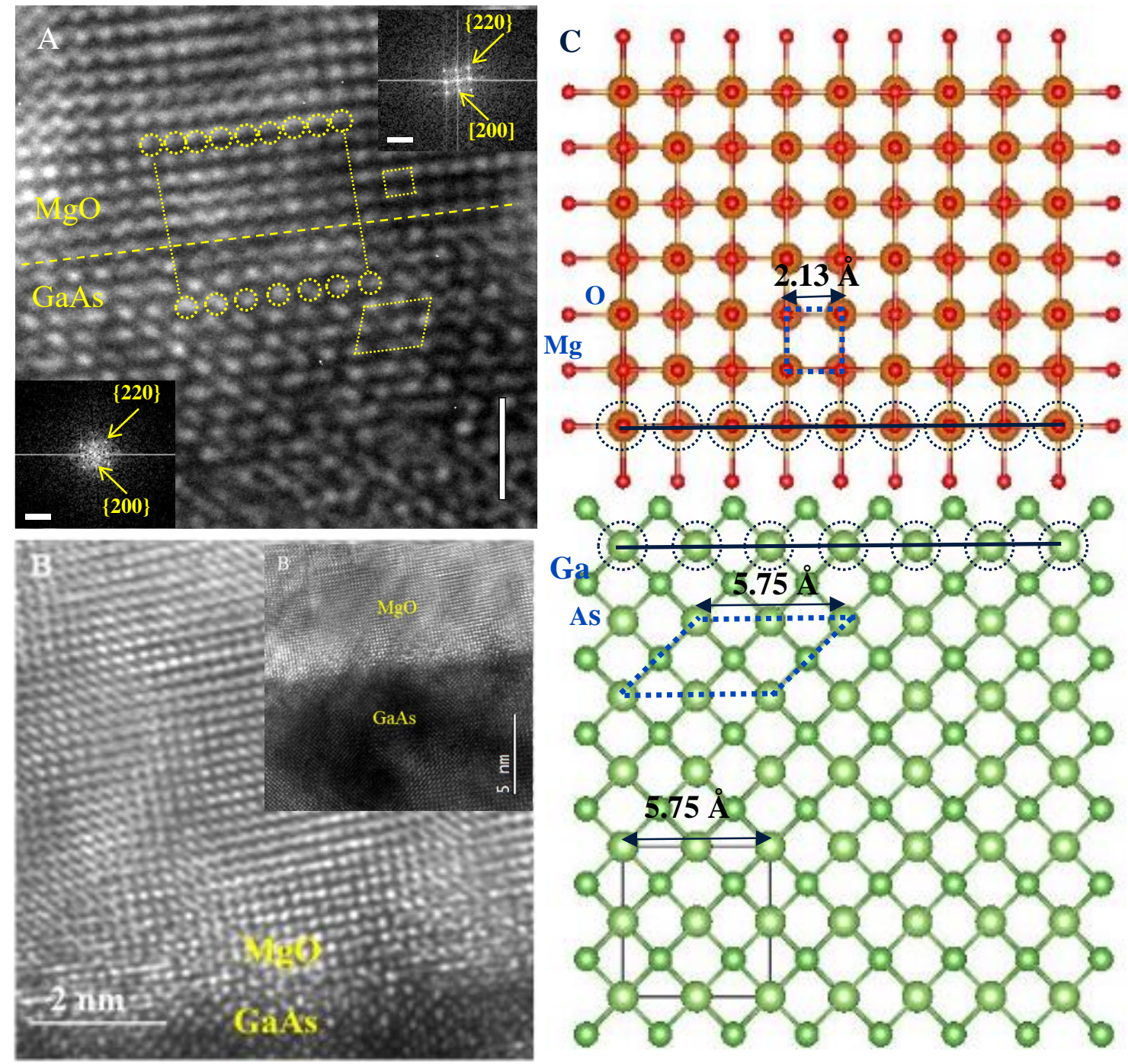
Figure 5.

A) and B) cross sectional HRTEM micrographs of MgO/GaAs (100), the inset in B is a larger area of the film. C) A model structure constructed in such a way that $\mathrm{MgO}$ (100) plane is parallel to GaAs (100). The square and parallelogram shown by blue dotted lines on $\mathrm{MgO}$ and GaAs in the model structure, respectively, correspond to those marked in yellow dotted lines on the TEM micrograph A. The $4: 3$ superstructure consisting of $4 \mathrm{MgO}$ (100) unit cells on top of $3 \mathrm{GaAs}$ (100) unit cells is shown by the yellow dotted circles drawn in TEM micrograph A. In the model structure, dotted circles and black lines drawn show the 4:3 relationship

The $\mathrm{MgO} / \mathrm{GaAs}$ model structure shown in Figure 5C is constructed in such a way that $\mathrm{MgO}$ (100) and GaAs (100) planes are parallel and this model structure helps to interpret the epitaxial growth of $\mathrm{MgO}$ (100) on top of GaAs (100). The square and parallelogram shown by blue dotted lines on $\mathrm{MgO}$ and GaAs, respectively, in the model structure, correspond to those marked in yellow dotted lines on the TEM micrograph in Figure 5A. In addition, distances between adjacent (100) planes (d space) in $\mathrm{MgO}$ and GaAs in the model structure are the same as those in the TEM micrograph. The XRD peak for MgO (200) at $42.1^{\circ}$ in Figure 2 corresponds to the d spacing in the TEM micrograph of MgO. Both TEM and XRD results clearly indicate the presence of $\mathrm{MgO}$ [100] $\| \mathrm{GaAs}$ [100], heteroepitaxial relationship in spite of $34.2 \%$ of lattice misfit. Despite the higher misfit, the epitaxial $\mathrm{MgO}(100)$ is grown on $\mathrm{GaAs}(100)$ due to the $4: 3$ relationship (4 aMgO $: 3 \mathrm{aGaAs}$ ) between $\mathrm{MgO}(100)$ and $\mathrm{GaAs}(100)[1]$. The formation of a 4:3 superstructure reduces the lateral misfit between $\mathrm{MgO}(100)$ and $\mathrm{GaAs}(100)$ to $\approx 0.65 \%$. The 4:3 superstructure consisting of $4 \mathrm{MgO}(100)$ unit cells on top of $3 \mathrm{GaAs}(100)$ unit cells is shown by the yellow dotted circles drawn, which evidences the epitaxial growth with $\mathrm{MgO}(100)[001] \|$ GaAs(100)[001]. In the model structure, the dotted circles and the black lines drawn show the 4:3 relationship. These results confirm the epitaxial growth of $\mathrm{MgO}$ (100) on top of GaAs (100). The ordered $\mathrm{MgO}$ layer is continued from the interface towards the film surface as shown by Figure 5B. The epitaxial growth of $\mathrm{MgO}$ also indicates that the preparation of GaAs (100) substrate by Ar sputtering and subsequent annealing provides a clean and flat surface for the growth of epitaxial $\mathrm{MgO}$ (100) layer on top of GaAs (100)

\subsection{Reaction of $\mathrm{MgO}$ films with $\mathrm{NaOH}$}

\subsubsection{Scanning electron microscopy (SEM) data}


To investigate the reaction of $\mathrm{MgO}$ film with $\mathrm{NaOH}$, the $\mathrm{MgO}$ (100)/GaAs (100) sample was immersed inside a solution of $0.1 \mathrm{M} \mathrm{NaOH}$ for five hours at room temperature and SEM micrographs were collected as shown in Figure 6. $\mathrm{NaOH}$ was chosen as a typical alkaline medium where the water splitting reaction would occur using an alkaline membrane[33]). The plan view of the SEM micrograph in Figure 6A shows flake-like structures, with some protrusions in certain areas as shown by the $35^{\circ}$-tilt view of SEM micrograph in Figure 6B. The EDX data (not shown) obtained from white protruding regions show more $\mathrm{O}$ relative to dark areas suggesting that white protrusions are $\operatorname{Mg}(\mathrm{OH})_{2}$. These SEM micrographs show that $\mathrm{Mg}(\mathrm{OH})_{2}$ structures develop into a continuous porous network. Similar flake-like structures were reported for $\mathrm{Mg}(\mathrm{OH})_{2}$ formed on a $\mathrm{Mg}$ film after it was immersed in a saturated $\mathrm{Mg}(\mathrm{OH})_{2}$ solution[34]. The SEM micrograph in Figure 6B shows that flake-like $\mathrm{Mg}(\mathrm{OH})_{2}$ structures are formed on top of $\mathrm{MgO}$ and this is further confirmed by TEM micrographs shown below.

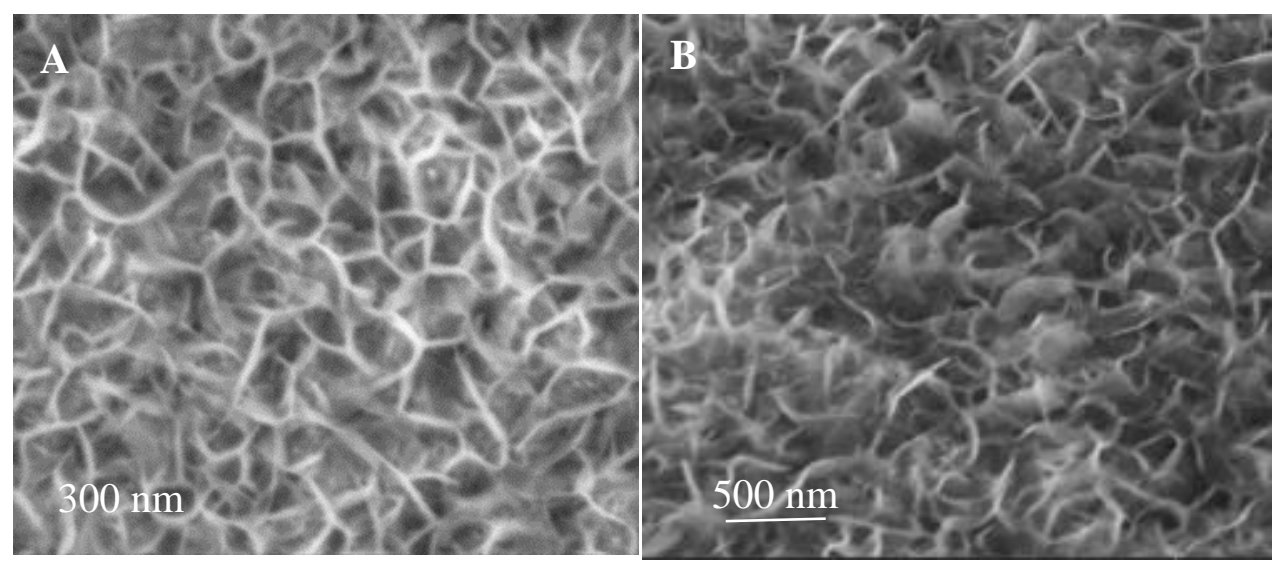

\section{Figure 6.}

SEM micrographs obtained after immersing $\mathrm{MgO} / \mathrm{GaAs}$ (100) inside a solution of $0.1 \mathrm{M} \mathrm{NaOH}$ for five hours. A) Plan view and B) $35^{\circ}$-tilt view. The $\mathrm{MgO}$ film was grown on GaAs (100) at $450{ }^{\circ} \mathrm{C}$.

\subsubsection{Transmission electron microscopy (TEM) and energy-dispersive X-ray spectroscopy (EDX) data}

To see the morphology and the interface between $\mathrm{Mg}(\mathrm{OH})_{2}$ and $\mathrm{MgO}$ after immersing $\mathrm{MgO}$ (100)/GaAs (100) in a solution of 0.1 M NaOH for five hours, TEM analysis was carried out. Figures 7A and 7B present cross sectional TEM micrographs and Figure 7C presents EDX spectra for the regions specified in Figure 7A. The EDX spectrum collected from GaAs, region 1, shows peaks only for As and $\mathrm{Ga}$ as expected. The presence of $\mathrm{MgO}$ is shown by the EDX spectrum taken from region 2. The EDX 
spectrum collected form region 3 shows peaks for $\mathrm{Mg}$ and $\mathrm{Pt}$, which was deposited prior to ion-beam milling during the preparation of the lamella for TEM analysis. This data shows that the presence of $\mathrm{Pt}$ in between $\mathrm{Mg}(\mathrm{OH})_{2}$ protrusions. Less intense peaks for $\mathrm{Mg}$ and $\mathrm{O}$ and an intense peak for $\mathrm{Pt}$ are shown by the spectrum collected from region 4 indicating the possible presence of $\operatorname{Mg}(\mathrm{OH})_{2}$ away from the $\mathrm{MgO}$ layer. $\mathrm{Mg}$ is not present in region 5 but peaks for $\mathrm{Pt}$ and $\mathrm{Ga}$ are present. $\mathrm{Cu}$ shown in EDX spectra originates from $\mathrm{Cu}$ TEM grid.
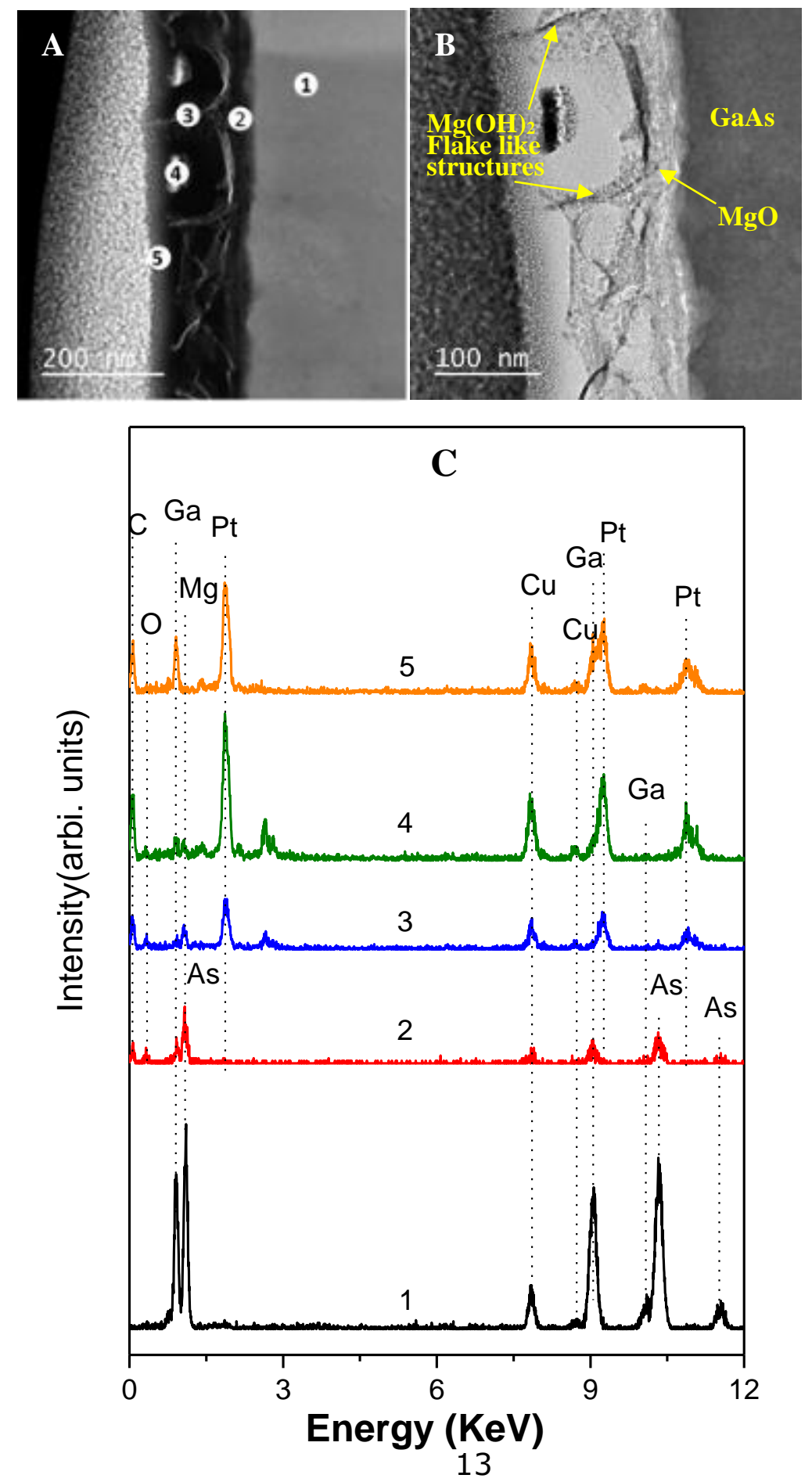


\section{Figure 7.}

A) and B) cross sectional TEM micrographs obtained after immersing $\mathrm{MgO} / \mathrm{GaAs}$ (100) inside a solution of $0.1 \mathrm{M} \mathrm{NaOH}$ for five hours. C) EDX spectra for the specified regions in Figure 7A.

Figure 7B may indicate flake-like $\mathrm{Mg}(\mathrm{OH})_{2}$ structures formed on the $\mathrm{MgO}$ film after it reacts with $\mathrm{NaOH}$. The sub-surface $\mathrm{MgO}$ is dense, whereas the surface has less dense and flake-like $\mathrm{Mg}(\mathrm{OH})_{2}$ structures. These flake-like $\mathrm{Mg}(\mathrm{OH})_{2}$ structures are also identified as possible structures in the SEM images shown in Figure 6. The TEM micrographs further show that these protrusions grow up to $25 \mathrm{~nm}$ above the $\mathrm{MgO}$ surface, which is also confirmed by the EDX data in Figure 7C. Similar growth of $\mathrm{Mg}(\mathrm{OH})_{2}$ on $\mathrm{Mg}$ surface was observed previously [34]. These results indicate that within the experimental conditions $\mathrm{NaOH}$ reacts with $\mathrm{MgO}$ to form $\mathrm{Mg}(\mathrm{OH})_{2}$ at some depth while still the underneath $\mathrm{MgO}$ layer stayed in contact with the GaAs substrate.

As mentioned in the introduction section, the wide band gap $\mathrm{MgO}$ allows passing the whole range of solar radiation. However, to use $\mathrm{MgO}$ films as a light penetrating protective layer for photo catalysts to avoid photo corrosion, the $\mathrm{MgO}$ film must be stable and able to transfer charge carriers from the semiconductor to the surface of $\mathrm{MgO}$. One of the main factors that determines the charge carrier transfer is the band alignments at the interface. Figure 8 shows a schematic band alignment diagram for interfaces of $\mathrm{MgO} / \mathrm{GaAs}$ and $\mathrm{MgO} / \mathrm{GaInP}_{2}$ as well as $\mathrm{MgO}$ defect states derived from previously reported data for $\mathrm{MgO} / \mathrm{GaAs}$ [16], GaInP2/GaAs [35], and $\mathrm{MgO}$ [36]. Based on band alignments of the GaAs and $\mathrm{MgO}$ interface, electrons cannot be transferred from $\mathrm{GaAs}$ to the $\mathrm{MgO}$ conduction band [16].

Solar cells are used in photo electro chemical (PEC) water splitting but they are prone to photocorrosion immediately after contacting with solutions or electrolytes. Therefore, there is a need for protective interlayer between the solar cell surface and electrolytes [37, 38]. To use $\mathrm{MgO}$ as a protection layer for solar cells with a top layer of $\mathrm{GaInP}_{2}, \mathrm{MgO}$ must be stable under reaction conditions and it must be able to transfer electrons efficiently (from $\mathrm{GaInP}_{2}$ to $\mathrm{MgO}$ film). This depends on the band alignments of the interface of $\mathrm{GaInP}_{2}$ and $\mathrm{MgO}$. Based on the band alignments of the interface of $\mathrm{GaInP}_{2}$ and $\mathrm{MgO}$ shown in Figure 8, any possible electron injection from semiconductor surfaces to $\mathrm{MgO}$ would occur via defects or electron tunneling. The latter strongly depends on the thickness of the $\mathrm{MgO}$ layer and in general tunneling occurs only with oxide layers of thickness less than $\approx 2-3 \mathrm{~nm}$. In $\mathrm{MgO}$, various defect centers such as oxygen vacancies (F-center defects), Mg vacancies (V-center defects), neutral Mg + neutral $\mathrm{O}$ vacancies (P center, Schottky defects), and interstitial oxygen etc...co-exist [36]. Some of 
these defect states reported previously are included in the schematic band alignment diagram shown in Figure 8[36]. Based on the band positions of $\mathrm{MgO}$ defect states, electrons from $\mathrm{GaAs}$ and $\mathrm{GaInP}_{2}$ can be injected to $\mathrm{MgO}$ films through defect states if they are present in the epitaxial $\mathrm{MgO}$ films. However, in order to use $\mathrm{MgO}$ as a protection layer, the stability of the $\mathrm{MgO}$ film under reaction conditions in the presence of photoreactions also needs to be considered. The reaction of $\mathrm{MgO}$ films with $\mathrm{NaOH}$ leads to form flake-like $\mathrm{Mg}(\mathrm{OH})_{2}$ structures at the upper layers while the underneath seems to indicate that $\mathrm{MgO}$ is still in contact with GaAs. Considering both stability of $\mathrm{MgO}$ under alkaline conditions and electron transferability from semiconductor surfaces to $\mathrm{MgO}$ through defect states, the $\mathrm{MgO}$ films can be considered for further studies as a protection layer for photo catalysts in photo electrochemical processes.

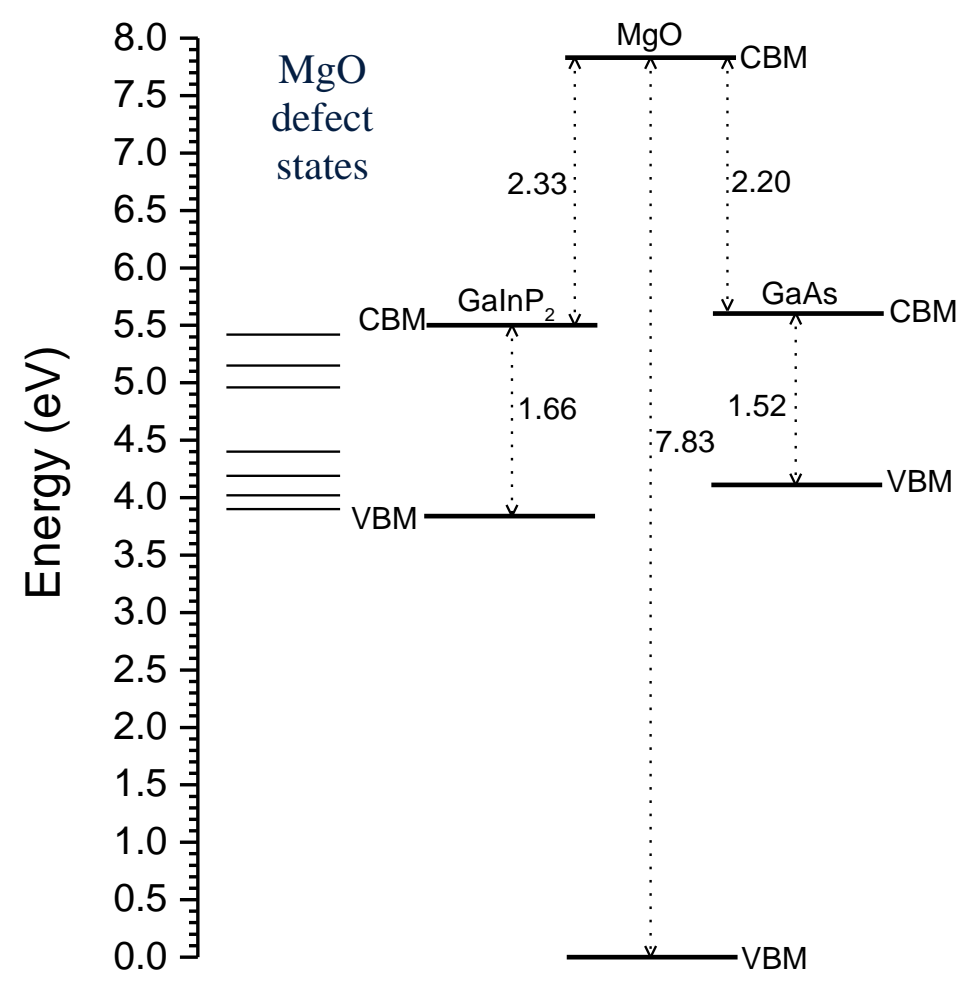

\section{Figure 8.}

Schematic band alignment diagram for interfaces of $\mathrm{MgO} / \mathrm{GaAs}$ and $\mathrm{MgO} / \mathrm{GaInP}_{2}$ as well as $\mathrm{MgO}$ defect states derived from previously reported data for $\mathrm{MgO} / \mathrm{GaAs}$ [16], GaInP2/GaAs [35], and $\mathrm{MgO}$ [36]. All energies are in $\mathrm{eV}$. 


\section{Conclusions}

The preparation procedure of the GaAs (100) substrate by Ar ion sputtering and subsequent annealing without any wet chemical methods provides a clean and smooth surface for the growth of epitaxial $\mathrm{MgO}$ films. AES results show that stoichiometric $\mathrm{MgO}$ is grown without other impurities within the detection limit of the spectrometer. XRD results show that better crystalline order can be achieved at the growth temperature in the range of $400-450{ }^{\circ} \mathrm{C}$. Further, XRD patterns indicate that the $\mathrm{MgO}$ film has grown predominantly in the cubic phase with the (100) plane parallel to the GaAs (100) substrate. HRTEM results have confirmed the epitaxial growth of $\mathrm{MgO}$ on $\mathrm{GaAs}$ (100) with $\mathrm{MgO}$ (100)[001] $\|$ GaAs (100)[001]. Despite the higher misfit, the epitaxial MgO (100) is grown on GaAs (100) due to the $4: 3$ relationship ( $4 \mathrm{aMgO}: 3 \mathrm{aGaAs}$ ) between $\mathrm{MgO}$ (100) and GaAs (100). The formation of a 4:3 superstructure reduces the lateral misfit between $\mathrm{MgO}$ (100) and $\mathrm{GaAs}$ (100) to $\approx 0.65 \%$. When $\mathrm{MgO}$ film is exposed to air, it reacts with $\mathrm{H}_{2} \mathrm{O}$ and $\mathrm{CO}_{2}$ to form hydroxides and carbonates, respectively, on the top layers of the $\mathrm{MgO}$ film. The reaction of $\mathrm{MgO}$ film with $\mathrm{NaOH}$ leads to flake-like structures with some protrusions, which develop into a continuous porous network. These flake-like structures are attributed to $\mathrm{Mg}(\mathrm{OH})_{2}$ and appear to be present only on the surface and near surface while still the underneath was composed of $\mathrm{MgO}$ layer, in contact with the GaAs substrate.

\section{References}

[1] S.B. Wang, A. Sarkar, M. Gruber, R. Koch, Epitaxy and stress of MgO/GaAs(001) heterostructures, J. Appl. Phys., 114 (2013) 154511.

[2] A. Masuda, K. Nashimoto, Orientation of MgO Thin Films on Si(100) and GaAs(100) Prepared by Electron-Beam Evaporation, Japanese Journal of Applied Physics, 33 (1994) L793-L796.

[3] W.Y. Hsu, R. Raj, MgO epitaxial thin-films on (100) GaAs as a substrate for the growth of oriented $\mathrm{PbTiO}_{3}$, Applied Physics Letters, 60 (1992) 3105-3107.

[4] X. Jiang, R. Wang, R.M. Shelby, R.M. Macfarlane, S.R. Bank, J.S. Harris, S.S.P. Parkin, Highly spin-polarized room-temperature tunnel injector for semiconductor spintronics using $\mathrm{MgO}(100)$, Phys. Rev. Lett., 94 (2005) 056601.

[5] S. Chromik, M. Spankova, I. Vavra, J. Liday, P. Vogrincic, P. Lobotka, Preparation and structural properties of MgO films grown on GaAs substrate, Applied Surface Science, 254 (2008) 3635-3637. [6] T.W. Kim, Y.S. You, Microstructural and electrical properties of $\mathrm{MgO}$ thin films grown on $\mathrm{p}-\mathrm{GaAs}$ (100) substrates, Mater. Res. Bull., 36 (2001) 747-754. 
[7] A. Sarkar, S.B. Wang, W. Grafeneder, M. Arndt, R. Koch, Ultrathin MgO diffusion barriers for ferromagnetic electrodes on GaAs(001), Nanotechnology, 26 (2015) 165203.

[8] Y. Lu, J.C. Le Breton, P. Turban, B. Lépine, P. Schieffer, G. Jézéquel, Measurement of the valence-band offset at the epitaxial $\mathrm{MgO}-\mathrm{GaAs}(001)$ heterojunction by x-ray photoelectron spectroscopy, Applied Physics Letters, 88 (2006) 042108.

[9] W. Prusseit, S. Corsépius, F. Baudenbacher, K. Hirata, P. Berberich, H. Kinder, Epitaxial growth of $\mathrm{YBa}_{2} \mathrm{Cu}_{3} \mathrm{O}_{7}$ films on GaAs with MgO buffer layers, Applied Physics Letters, 61 (1992) 1841-1843. [10] K. Nashimoto, D.K. Fork, T.H. Geballe, Epitaxial-growth of MgO on GaAs(001) for growing epitaxial $\mathrm{BaTiO}_{3}$ thin-films by pulsed laser deposition, Applied Physics Letters, 60 (1992) 1199-1201. [11] D.K. Fork, K. Nashimoto, T.H. Geballe, Epitaxial $\mathrm{YBa}_{2} \mathrm{Cu}_{3} \mathrm{O}_{7}-\delta$ on $\mathrm{GaAs}(001)$ using buffer layers, Applied Physics Letters, 60 (1992) 1621-1623.

[12] J. Bruley, S. Stemmer, F. Ernst, M. Rühle, W.-Y. Hsu, R. Raj, Nanostructure and chemistry of a (100)MgO/(100) GaAs interface, Applied Physics Letters, 65 (1994) 564-566.

[13] R. Soto, S. Mergui, P.E. Schmidt, Electrical and mechanical properties of $\mathrm{MgO}$ thin films on GaAs, Thin Solid Films, 308-309 (1997) 611-614.

[14] L.S. Hung, L.R. Zheng, T.N. Blanton, Epitaxial growth of MgO on (100)GaAs using ultrahigh vacuum electron-beam evaporation, Applied Physics Letters, 60 (1992) 3129-3131.

[15] Y. Li, Y. Chye, Y.F. Chiang, K. Pi, W.H. Wang, J.M. Stephens, S. Mack, D.D. Awschalom, R.K. Kawakami, Inversion of Ferromagnetic Proximity Polarization by MgO Interlayers, Phys. Rev. Lett., $100(2008) 237205$.

[16] Y. Lu, J.C. Le Breton, P. Turban, B. Lepine, P. Schieffer, G. Jezequel, Measurement of the valence-band offset at the epitaxial $\mathrm{MgO}-\mathrm{GaAs}(001)$ heterojunction by x-ray photoelectron spectroscopy, Applied Physics Letters, 88 (2006) 042108

[17] M.Z. Tseng, C. Nguyen, E. Tarsa, L.D. Chang, E.L. Hu, H. Kroemer, Temperature-dependent mobility of a GaAs/AlGaAs heterostructure after deposition of $\mathrm{MgO}$ and superconducting $\mathrm{YBa}_{2} \mathrm{Cu}_{3} \mathrm{O}_{7}-\mathrm{x}$, Applied Physics Letters, 61 (1992) 601-603.

[18] C.T. Foxon, J.A. Harvey, B.A. Joyce, The evaporation of GaAs under equilibrium and nonequilibrium conditions using a modulated beam technique, Journal of Physics and Chemistry of Solids, 34 (1973) 1693-1701.

[19] C. Xu, J.S. Burnham, R.M. Braun, S.H. Goss, N. Winograd, Tilting in the arsenic-induced c(4×4) reconstruction of the GaAs $\{001\}$ surface, Physical Review B, 52 (1995) 5172-5178. 
[20] J. Herfort, H.-P. Schönherr, B. Jenichen, Magnetic and structural properties of ultrathin epitaxial Fe3Si films on GaAs(001), J. Appl. Phys., 103 (2008) 07B506.

[21] B.D. Schultz, C. Adelmann, X.Y. Dong, S. McKernan, C.J. Palmstrøm, Phase formation in the thin film Fe/GaAs system, Applied Physics Letters, 92 (2008) 091914.

[22] S. Tanuma, C.J. Powell, D.R. Penn, Calculations of electorn inelastic mean free paths. II. Data for 27 elements over the 50-2000 eV range, Surface and Interface Analysis, 17 (1991) 911-926.

[23] J.N. Wilson, R.M. Dowler, H. Idriss, Adsorption and reaction of glycine on the rutile $\mathrm{TiO}_{2}(011)$ single crystal surface, Surface Science, 605 (2011) 206-213.

[24] G. Ertl; J. Kuppers; Low Energy Electrons and Surface Chemistry 2nd Edition ed., Wiley-VCH, Weinheim, Federal Republic of Germany, 1986.

[25] M.P. Seah, W.A. Dench, Quantitative electron spectroscopy of surfaces: A standard data base for electron inelastic mean free paths in solids, Surface and Interface Analysis, 1 (1979) 2-11.

[26] P. Casey, E. O'Connor, R. Long, B. Brennan, S.A. Krasnikov, D. O'Connell, P.K. Hurley, G. Hughes, Growth, ambient stability and electrical characterisation of $\mathrm{MgO}$ thin films on silicon surfaces, Microelectron. Eng., 86 (2009) 1711-1714.

[27] D.K. Aswal, K.P. Muthe, S. Tawde, S. Chodhury, N. Bagkar, A. Singh, S.K. Gupta, J.V. Yakhmi, XPS and AFM investigations of annealing induced surface modifications of $\mathrm{MgO}$ single crystals, Journal of Crystal Growth, 236 (2002) 661-666.

[28] Y. Yao, S. Okur, L.A. Lyle, G.S. Tompa, T. Salagaj, N. Sbrockey, R.F. Davis, L.M. Porter, Growth and characterization of $\alpha-, \beta-$, and $\epsilon$-phases of $\mathrm{Ga}_{2} \mathrm{O}_{3}$ using MOCVD and HVPE techniques, Materials Research Letters, 6 (2018) 268-275.

[29] W.B. Pearson, A handbook of lattice spacings and structures of metals and alloys: International series of monographs on metal physics and physical metallurgy, Elsevier, 2013.

[30] S. Redfern, E. Salje, Spontaneous strain and the ferroelastic phase transition in $\mathrm{As}_{2} \mathrm{O}_{5}$, Journal of Physics C: Solid State Physics, 21 (1988) 277.

[31] P. Ballirano, A. Maras, Refinement of the crystal structure of arsenolite, $\mathrm{As}_{2} \mathrm{O}_{3}$, Zeitschrift für Kristallographie-New Crystal Structures, 217 (2002) 177-178.

[32] M. Jansen, Crystal Structure of As2O5, Angewandte Chemie Int. Ed., 16 (177) 314-315.

[33] M.A. Khan, I. Shankiti, A. Ziani, N. Wehbe, H. Idriss, A stable integrated photo-electrochemical reactor for $\mathrm{H}_{2}$ production from water with $\mathrm{STH}$ of $18 \%$ at 15 suns and $13 \%$ at 207 suns., Angewandte Chemie Submitted, (2020). 
[34] S.H. Salleh, S. Thomas, J.A. Yuwono, K. Venkatesan, N. Birbilis, Enhanced hydrogen evolution on $\mathrm{Mg}(\mathrm{OH})_{2}$ covered $\mathrm{Mg}$ surfaces, Electrochimica Acta, 161 (2015) 144-152.

[35] S. Froyen, A. Zunger, A. Mascarenhas, Polarization fields and band offsets in GaInP/GaAs and ordered/disordered GaInP superlattices, Applied Physics Letters, 68 (1996) 2852-2854.

[36] N. Pathak, P.S. Ghosh, S.K. Gupta, R.M. Kadam, A. Arya, Defects induced changes in the electronic structures of $\mathrm{MgO}$ and their correlation with the optical properties: a special case of electron-hole recombination from the conduction band, RSC Advances, 6 (2016) 96398-96415. [37] E. Verlage, S. Hu, R. Liu, R.J.R. Jones, K. Sun, C.X. Xiang, N.S. Lewis, H.A. Atwater, A monolithically integrated, intrinsically safe, $10 \%$ efficient, solar-driven water-splitting system based on active, stable earth-abundant electrocatalysts in conjunction with tandem III-V light absorbers protected by amorphous TiO2 films, Energy \& Environmental Science, 8 (2015) 3166-3172. [38] L. Kornblum, D.P. Fenning, J. Faucher, J. Hwang, A. Boni, M.G. Han, M.D. Morales-Acosta, Y. Zhu, E.I. Altman, M.L. Lee, C.H. Ahn, F.J. Walker, Y. Shao-Horn, Solar hydrogen production using epitaxial $\mathrm{SrTiO}_{3}$ on a GaAs photovoltaic, Energy \& Environmental Science, 10 (2017) 377-382. 


\section{Figure Captions}

Figure 1. Auger electron spectra before (black) and after (blue) deposition of an $\mathrm{MgO}$ film on GaAs (100) at the following experimental conditions. The GaAs (100) substrate was cleaned by Ar ion sputtering at $500{ }^{\circ} \mathrm{C}$ for 30 minutes and subsequent annealing at $550{ }^{\circ} \mathrm{C}$ for one hour. The $\mathrm{MgO}$ film was grown at $450{ }^{\circ} \mathrm{C}$-substrate temperature by evaporating $\mathrm{Mg}$ under $5.0 \times 10^{-6}$ Torr of $\mathrm{O}_{2}$ for three hours. The $\mathrm{Mg}$ cell temperature was kept at $240{ }^{\circ} \mathrm{C}$. A) The $\mathrm{dN}(\mathrm{E}) / \mathrm{dE}$ AES O KLL region before and after deposition. B) The dN(E)/dE AES Mg KLL, Ga LMM and As LMM regions before and after deposition.

Figure 2. X-ray diffraction pattern of an $\mathrm{MgO}$ film grown on $\mathrm{GaAs}(100)$ at $450{ }^{\circ} \mathrm{C}$. The inset is a magnifying region of the GaAs (200) and $\mathrm{MgO}$ (200) diffraction patterns.

Figure 3. SEM micrographs of an $\mathrm{MgO}$ film grown on GaAs (100) at $450{ }^{\circ} \mathrm{C}$. A) Right after preparing the $\mathrm{MgO}$ film. After exposing the $\mathrm{MgO}$ film to air $\mathrm{B}$ ) for $\approx$ six hours and $\mathrm{C}$ ) for 8 days. D) After immersing $\mathrm{MgO} / \mathrm{GaAs}(100)$ inside water for five hours.

Figure 4. A) A cross sectional TEM micrograph of $\mathrm{MgO} / \mathrm{GaAs}$ (100) lamella prepared by FIB milling. Prior to ion-beam milling, layers of $\operatorname{Ir}(\approx 10 \mathrm{~nm}), \mathrm{C}(\approx 35 \mathrm{~nm})$ and $\mathrm{Pt}(\approx 500 \mathrm{~nm})$ were deposited on top of the $\mathrm{MgO}$ film to preserve the surface from damage by high energy $\mathrm{Ga}^{+}$ion beam used for the milling process. B) EDX spectra obtained from the regions 1 and 2 specified in A. C) and D) SAED patterns of $\mathrm{MgO}$ and $\mathrm{GaAs}$, respectively. Insets present TEM micrographs of $\mathrm{MgO}$ and $\mathrm{GaAs}$.

Figure 5. A) And B) cross sectional TEM micrographs of MgO/GaAs (100). C) A model structure constructed in such a way that $\mathrm{MgO}$ (100) plane is parallel to GaAs (100). The square and parallelogram shown by blue dotted lines on $\mathrm{MgO}$ and $\mathrm{GaAs}$ in the model structure, respectively, correspond to those marked in yellow dotted lines on the TEM micrograph A. The $4: 3$ superstructure consisting of $4 \mathrm{MgO}$ (100) unit cells on top of 3 GaAs (100) unit cells is shown by the yellow dotted circles drawn in TEM micrograph A. In the model structure, dotted circles and black lines drawn show the 4:3 relationship.

Figure 6. SEM micrographs obtained after immersing $\mathrm{MgO} / \mathrm{GaAs}$ (100) inside a solution of $0.1 \mathrm{M}$ $\mathrm{NaOH}$ for five hours. A) Plan view and B) $35^{\circ}$-tilt view. The $\mathrm{MgO}$ film was grown on $\mathrm{GaAs}(100)$ at $450{ }^{\circ} \mathrm{C}$.

Figure 7. A) and B) cross sectional TEM micrographs obtained after immersing $\mathrm{MgO} / \mathrm{GaAs}$ (100) inside a solution of $0.1 \mathrm{M} \mathrm{NaOH}$ for five hours. C) EDX spectra for the specified regions in Figure 7A.

Figure 8. Schematic band aligniment diagram for interfaces of $\mathrm{MgO} / \mathrm{GaAs}$ and $\mathrm{MgO} / \mathrm{GaInP}_{2}$ as well as $\mathrm{MgO}$ defect states derived from previously reported data for $\mathrm{MgO} / \mathrm{GaAs}$ [16], $\mathrm{GaInP}_{2} / \mathrm{GaAs}$ [35], and $\mathrm{MgO}$ [36]. All energies are in eV. 